Original Research Paper

\title{
Comparison of Ferrous Ion Chelating Properties of Collagen Peptides from Dried and Fresh Cod Skin
}

\author{
Mengqian Chen, Cen Chen, Junchao Wu, Jiayuan Bi, Han Jiang and Guangrong Huang* \\ Key Lab of Marine Food Quality and Hazard Controlling Technology of Zhejiang Province, \\ College of Life Sciences, China Jiliang University, Hangzhou310018, China
}

Article history

Received: 25-03-2021

Revised: 29-05-2021

Accepted: 11-06-2021

Corresponding Author: Guangrong Huang

Key Lab of Marine Food Quality and Hazard Controlling Technology of Zhejiang Province, College of Life Sciences, China Jiliang University, Hangzhou310018, China

E-mail: grhuang@126.com

\begin{abstract}
Fish skin is a potential source of collagen and collagen is a protein source of bioactive peptides including iron chelating peptides. The aim of this study is to compare physicochemical properties of collagen extracted from fresh and dried cod skin and the ferrous ion chelating properties of collagen hydrolysates. Then the fresh and dried cod skin extracted collagen was hydrolyzed with collagenase to obtain collagen peptides. The collagen peptides chelated ferrous ion. The results showed that cod skin is a good source of collagen which is accounted for $95.17 \%$ of the total proteins. The collagen from fresh cod skin was slightly easier to be hydrolyzed than that from dried cod fish. Respectively, at the same hydrolysis conditions the maximum degree of hydrolysis were 13.64 and $12.57 \%$. The collagen from fresh cod skin had better iron chelating ability than that from dried cod skin, the iron chelating abilities were 32.16 and $23.12 \%$. The UV-Vis spectroscopy of collagen peptides obtained from fresh or dried cod skin showed the same maximum absorption peaks near 230 and $250 \mathrm{~nm}$. When combined with ferrous ion, the maximum of absorption peak is migrated. SDS-PAGE proved that the molecular weight of collagen is $180 \mathrm{k}$ Da more or less. The electron microscopy and infrared spectra showed that collagen peptide could chelate with ferrous ion through $-\mathrm{NH}$ and $\mathrm{C}=\mathrm{O}$. Fresh cod skin extracted collagen has a higher degree of hydrolysis and is more favorable to chelate ferrous ion to produce peptide ferrous chelate, but they have a similar structure.
\end{abstract}

Keywords: Cod Skin, Collagen Peptides, Ferrous Ion, Chelation, Extraction

\section{Introduction}

Iron is an essential mineral of human body and also the most prone trace elements to make metabolic disorders (Toxqui and Vaquero, 2015). Many key enzymes in the body which perform vital functions require iron. If our body does not obtain a certain amount of iron, can lead to variety of diseases (Wang et al., 2020). Iron-deficiency diseases are one of the most common diseases in developing countries (Eckert et al., 2016), which have affected $24.8 \%$ of the world population (Toxqui and Vaquero, 2015). The most common form of iron deficiency is iron-deficiency anemia, which has become one of the universal nutritional health problems. Also iron deficiency can lead to energy metabolic disorders, immune injury and cognitive dysplasia (De la Hoz et al., 2014; Ji et al., 2012).

Iron supplementation in diet is an effective way to intake iron (Chen et al., 2017). But the iron utilization rate of the mixed diet is low (Navas-Carretero et al., 2008; Wu et al., 2019). General animal sources of heme iron in the body of high absorption efficiency, such as beef heme iron, its absorption rate is $22 \%$, which is greatly higher than the plant source of 1 5\% (Hurrell and Egli, 2010; Toxqui et al., 2013). Heme iron is red; if we adding it to food will affect the color of the product and even change the properties of food (Ma et al., 2019; Wu et al., 2020), in conclusion its application is very limited. Iron supplements can be prepared by combining iron with salts or peptides (Le Vo et al., 2020a). Studies have shown that, compared with salt, iron chelating peptides have a better palatability, fewer side effects and a higher absorption rate. It can be an ideal iron supplement. At present, many foreign scholars have begun to study small peptide iron chelates (Le Vo et al., 2020b) and domestic researchers have also started to continue to pay attention to iron chelates which can be absorbed by the small intestine through the peptide absorption channel, to reduce the competition between ferrous ions and other ions in the ion absorption channel transport process (El-Hawary et al., 1975; Mazariegos et al., 2004). 
Collagen is a structural protein with biological functions, which is widely used in the pharmaceutical, cosmetic and food industries (Ahmed et al., 2020; Sampath Kumar and Nazeer, 2013). Cod is a kind of cold water fish living in the bottom of the ocean and the middle and lower layers of the deep sea. At present it is a fish species which is widely distributed in all oceans of the world and a large catch amount. Also has a high economic value. In the process of production and trade, the waste of cod byproducts is serious (Rustad et al., 2011; Sousa et al., 2020). The dry matter of cod skin contains more than $50 \%$ collagen, which is rich in amino acids and has high nutritional value. Moreover, relevant studies have shown that the intake of fish skin collagen peptide will not cause an allergic reaction (Kristinsson and Rasco, 2000; Nomura et al., 1996). Cod skin is a good raw material for the preparation of high-quality collagen peptide.

In the traditional extraction method, fresh cod skin is commonly used to extract collagen. However, compared with dried cod skin, fresh cod skin has the disadvantages like not easy to preserve, short storage time and high transportation cost. In this study, fresh cod skin and dried cod skin were used as raw materials respectively and collagen was extracted by the same method. The hydrolysis degree and iron chelating rate of the collagen were measured to compare its basic physicochemical properties. Then the spectroscopic method is used to conduct an in-depth study and comparison of their structures.

\section{Materials}

Dried and fresh cod skin which was obtained from Qingdao Jincai Food Co., Ltd (Qingdao, China) and they were stored at 4 and $-20^{\circ} \mathrm{C}$ until the time of the experiment respectively. Collagenase I, bovine serum protein and hydroxyproline were obtained from Sigma-Aldrich Co. (St. Louis, MO, USA). The other chemical reagents used in this experiment were all analytical level and the water used was deionized water.

\section{Pretreatment of Cod Skins}

Cod skin treatment was conducted as reported method (Li et al., 2018) and modified it slightly. Washing the fresh cod skins with distilled water and removing the scales. Divide the fish skin into two parts, to get the dried cod skin, one of them is put in the constant temperature blast drying oven (Senxin Experimental Instrument Co., Shanghai, P.R. China) to dry at $40^{\circ} \mathrm{C}$ until there is no moisture is available. Then the cod skins were cut into 2 $\times 2 \mathrm{~cm}$ fragments and degreased with $10 \%$ isopropyl alcohol at a solid-solution ratio of $1: 20(w / v)$ at $4^{\circ} \mathrm{C}$ for 8 $\mathrm{h}$ to remove fat. Washing the skin with distilled water until the washed water became neutral. To remove noncollagen proteins, the skimmed fish skins were mixed with 10 volumes of $7.5 \% \mathrm{NaCl}$ for $12 \mathrm{~h}$.

\section{Extraction of Collagen from Cod Skins}

Refer to the reported method (Li et al., 2018). The fresh cod skins were cleaned with distilled water. It was manufactured into a pulp and soaked in $0.5 \mathrm{M}$ acetic acid at $4{ }^{\circ} \mathrm{C}$ for $24 \mathrm{~h}$ with the solid- solution ratio of $1: 50(w / v)$. The suspension was centrifuged at $10000 \mathrm{~g}$ for $10 \mathrm{~min}$ at $4{ }^{\circ} \mathrm{C}$ and the supernatant was collected, followed by vacuum filtration. The $\left(\mathrm{NH}_{4}\right)_{2} \mathrm{SO}_{4}$ was added to supernatants at $\mathrm{pH} 7.5$ to achieve a final concentration of $1.5 \mathrm{M}$. Then, the solution was centrifuged at $10000 \mathrm{~g}$ for $10 \mathrm{~min}$ at $4^{\circ} \mathrm{C}$ to collect the precipitate which would be dissolved in $0.5 \mathrm{M}$ acetic acid solution. The residue was re-extracted in $0.5 \mathrm{M}$ acetic acid for $24 \mathrm{~h}$. The combined supernatant was salted out to precipitate the protein. The solution was placed in a dialysis bag (MW8000-14000RC, diameter $34 \mathrm{~mm}$, Biomed Instruments Inc., USA) against $0.1 \mathrm{M}$ acetic acid and distilled water for $3 \mathrm{~d}$ at $4^{\circ} \mathrm{C}$, respectively. Replaced the solution every $2 \mathrm{~h}$ and store it in refrigerator at $4^{\circ} \mathrm{C}$ at night. The content of salt ions was detected with $\mathrm{BaCl}_{2}$ reagent until there was no precipitation. The dialysis samples were freeze-dried. Dried cod skins were extracted by the same method.

\section{Hydrolysis of Collagen}

Collagenase was used to hydrolyze the collagen extracted from fresh and dried fish skin. The enzymesubstrate ratio was $20 \mathrm{U} / \mathrm{mg}$, the substrate concentration was $8 \mathrm{mg} / \mathrm{mL}$. The enzymatic hydrolysis temperature was $33^{\circ} \mathrm{C}$ with the $\mathrm{pH}$ 7.0. The hydrolysate was taken out at different hydrolysis time (10360 min) and placed in a water bath to inactivate the enzyme at $100^{\circ} \mathrm{C}$ for $10 \mathrm{~min}$ immediately. Cool over ice for $20 \mathrm{~min}$. The supernatant was collected by centrifuging at $10000 \mathrm{~g}$ for $10 \mathrm{~min}$ to obtain the Peptides from Fresh Cod skin (PFC) and Peptides from Dried Cod skin (PDC).

\section{Analysis Methods}

\section{Proximate Composition of Cod Skin}

The proximate composition of cod skin, including ash, crude fat, moisture, crude protein and hydroxyproline content was based on the method of the Association of Official Analytical Chemists (AOAC). The nitrogen content is multiplied by 6.25 to get protein content. The fat was calculated by solet method. The moisture content was determined by direct drying. Ash is obtained by burning at high temperature. Chloramine $\mathrm{T}$ solution was added into the hydrolysate of fish skin and $p$-amino benzaldehyde was used as the chromogen reagent. Hydroxyproline content was determined by colorimetric method at $560 \mathrm{~nm} .12 .5$ was taken as the conversion factor (Edwards and O’Brien, 1980). 


\section{Degree of Hydrolysis}

The hydrolysate was added with equal volume of $20 \%$ $(v / w)$ trichloroacetic acid, stood at $5^{\circ} \mathrm{C}$ for $30 \mathrm{~min}$, centrifuged at $10000 \mathrm{~g}$ for $10 \mathrm{~min}$ and the supernatant was collected. With bovine serum protein as the standard curve, the protein content was determined with fooling phenol reagent (Schenck, 1951). The Degree of Hydrolysis (DH) was expressed as protein content in trichloroacetic acid percentage of total protein content.

\section{Sodium Dodecyl Sulphate-Polyacrylamide Gel Electrophoresis (SDS-PAGE)}

PFC, PDC and fresh and dried cod skin extracted collagen, were characterized by SDS-PAGE refers to the reported method (Yao et al., 2012). The samples were respectively configured into $2 \mathrm{mg} / \mathrm{mL}$ solution for loading. SDS-PAGE was performed with $8 \%$ separating gel, $4 \%$ stacking gel concentration. The loading volume is $3 \mu \mathrm{L}$, $120 \mathrm{~V}$ voltage for separating gel, $80 \mathrm{~V}$ voltage for stacking gel. Coomassie Bright Blue was dyed overnight and the decolorizing solution was decolorized until the bands were clear.

\section{Ferrous Ion Chelating Ability}

The chelating ability of ferrous ion was determined by the color reaction between ferrous ion and ferrozine solution (Gómez et al., 2020; Wu et al., 2017). Hydrolysates of PFC and PDC $(1 \mathrm{mg} / \mathrm{mL})$ were added with $2 \mathrm{~mL}$ of deionized water $(\mathrm{pH} 5.4-6.0)$ and shaken well. $0.1 \mathrm{~mL}$ of $1 \mathrm{~mm} \mathrm{FeCl}_{2}$ (dissolved in $30 \mathrm{mmol} / \mathrm{L}$ ascorbic acid) was added for reaction at room temperature for $30 \mathrm{~min} .0 .2 \mathrm{~mL}$ of $5 \mathrm{~mm}$ ferrozine solution was added for reaction at room temperature for $10 \mathrm{~min}$. The measured absorbance value at $562 \mathrm{~nm}$ is $\mathrm{A}_{1}$. The blank group was replaced with deionized water. The value of absorbance is $\mathrm{A}_{0}$. The formula is as Eq. (1):

Chelating ability $(\%)=\left(1-A_{1} / A_{0}\right) \times 100 \%$

\section{UV-Vis Spectroscopy}

According to the method of (Jiang et al., 2019), collagen peptide was dissolved in $0.5 \mathrm{M}$ acetic acid solution at a concentration of $0.2 \mathrm{mg} / \mathrm{mL}$. The $0.5 \mathrm{M}$ acetic acid solution was used as the baseline. The fullwavelength scan from $200 \mathrm{~nm}$ to $600 \mathrm{~nm}$ was determined using Shimadzu spectrophotometer UV2600 (Shimadzu Co., Ltd, Japan). The chelate was determined by the same method.

\section{Fourier Transform Infrared Spectroscopy (FTIR)}

Refer to the method of (Chen et al., 2019), $2 \mathrm{mg}$ collagen peptides and chelates were weighed respectively and mixed with $0.2 \mathrm{~g} \mathrm{KBr}$ to ground evenly. The mixture was pressed to a transparent sheet. FTIR spectra were got using an FTIR spectrophotometer (Thermo, Massachusetts, USA) with a spectral range from 4000 to $500 \mathrm{~cm}^{-1}$. The software of OMNIC 6.0 (Thermo Nicolet) was used for spectra data analysis.

\section{Scanning Electron Microscopy (SEM)}

SEM was used to detect the structure of fibrillar formed by PFC, PDC and their chelates. The surface morphology of the sample was observed by Field emission scanning electron microscope (SU8010, HITACHI, Japan) with the magnification of 2000 times.

\section{Circular Dichroism}

The concentration of collagen was set at $1 \mathrm{mg} / \mathrm{mL}$ for determination. Circular Dichroism (CD) measurements were performed using a Jasco J-815 spectropolarimeter (Jasco, Japan). Use a quartz cuvette (Hellma, Germany) with a length of $2 \mathrm{~mm}$. The scanning range was $190-240 \mathrm{~nm}$, the scanning speed was $100 \mathrm{~nm} / \mathrm{min}$ and the CD spectrum was obtained by three times scanning consecutively.

\section{Statistical Analysis}

All experiments were repeated three times and the data results were expressed as average values. SPSS software (IBM, Chicago, IL, USA) was used for statistical analysis of the data. Origin software (Origin Lab Co., Northampton, USA) was used for drawing and smoothing.

\section{Results}

\section{Compositions Analysis}

The compositions analysis of cod skin has been shown in Table 1. The data showed that the moisture content in wet fish skin was higher, which was $63.81 \%$, followed by the crude protein content, which was $34.15 \%$. The content of hydroxyproline was $2.6 \%$. According to the conversion coefficient of 12.5 (Edwards and O'Brien, 1980), the content of collagen was $32.5 \%$, accounting for $95.17 \%$ of the total protein content.

\section{Effect of Enzymatic Hydrolysis Time on DH}

According to (Fig.1), when the hydrolysis time was 10 $\mathrm{min}$, the DH of both dried and fresh cod skin was close to $2 \%$. From the trend of $\mathrm{DH}$, it could be observed that the DH from 0 to 240 min was in a direct proportion to the time and the DH from 240 to $360 \mathrm{~min}$ tended to be flat. The DH of collagen extracted from dried skin was $12.57 \%$ and that was extracted from fresh skin was $13.64 \%$ at $360 \mathrm{~min}$.

\section{Analysis of SDS-PAGE Pattern}

The SDS-PAGE pattern has been shown in Fig. 2. From Fig.2, the fresh and dried cod skin extracted 
collagen came out bands around $110 \mathrm{k}$ Da and $200 \mathrm{k}$ Da. The collagen extracted from dried cod skin had bands at 200 and $110 \mathrm{k} \mathrm{Da}$, but the bands were not obvious. Under experimental conditions there were no bands in the electrophoresis of PDC and PFC. This indicated that collagen had been hydrolyzed into small molecular polypeptides with a molecular weight of less than 10k Da.

\section{Chelation of Ferrous Ion by PDC and PFC}

As a new type of iron supplement, the determination of PDC and PFC for iron chelating activity have a vital effect. Figure 3 shows that both PDC and PFC have a chelating activity against ferrous ion. EDTA which was used as a control group in this ferrous chelating ability experiment. The ferrous ion chelating rate of EDTA is close to $100 \%$. As the increasing of collagen hydrolysis time, the chelating activity of PDC and PFC to ferrous ion increased continuously. The collagen peptide with a smaller molecular weight has a better chelating ability of ferrous ion. The chelation activity increased rapidly from 10 to $120 \mathrm{~min}$ and tended to be flat at 120 and $240 \mathrm{~min}$. The results indicated that PDC and PFC had a better chelating activity of ferrous ion at about $120 \mathrm{~min}$.

\section{UV-Vis Spectrum Properties}

From Fig. 4, PFC showed the maximum UV absorption wavelength at 225 and $258 \mathrm{~nm}$, while PDC showed the maximum UV absorption wavelength at 226 and $264 \mathrm{~nm}$, which was consistent with the characteristics of collagen. The information in the Fig. 4 showed that when PFC and PDC chelate with ferrous ion, the maximum absorption wavelengths of PFC and PDC shift to $218 \mathrm{~nm}$ and $219 \mathrm{~nm}$ respectively.

\section{FTIR Properties}

FTIR spectra in the range of $4000-500 \mathrm{~cm}^{-1}$ of PFC and PDC are presented in Fig. 5 (a). The absorption peak generated by N-H stretching vibration occurs in the range of $3400-3440 \mathrm{~cm}^{-1}$, the position is shifted after combining with hydrogen bond (Muyonga et al., 2004), which change to $3269.45 \mathrm{~cm}^{-1}$ and $3331.36 \mathrm{~cm}^{-1}$ respectively. In the amide I band, the absorption of $\mathrm{C}=\mathrm{O}$ stretching vibration ranges from 1600 to $1700 \mathrm{~cm}^{-1}$ and the absorption peaks generated by PFC and PDC in this band are both around $1655 \mathrm{~cm}^{-1}$. In the amide II band, the absorption peaks were 1547.05 and $1536.04 \mathrm{~cm}^{-1}$. In the amide III band, the absorption peaks of PFC were 1246.55, 1314.23 and 1398.76 $\mathrm{cm}^{-1}$, respectively. The absorption peaks of PDC were $1245.35,1308.13$ and $1393.83 \mathrm{~cm}^{-1}$. The ranges from 1200 to $1400 \mathrm{~cm}^{-1}$ is the characteristic absorption peak of the collagen infrared spectrum (amide III band).

Table 1: Composition analysis of cod skin (wet weight)

\begin{tabular}{lc}
\hline Composition & Proportion (\%) \\
\hline Moisture & 63.81 \\
Ash & 0.34 \\
Crude fat & 1.53 \\
Crude protein & 34.15 \\
Collagen & 32.50 \\
\hline
\end{tabular}

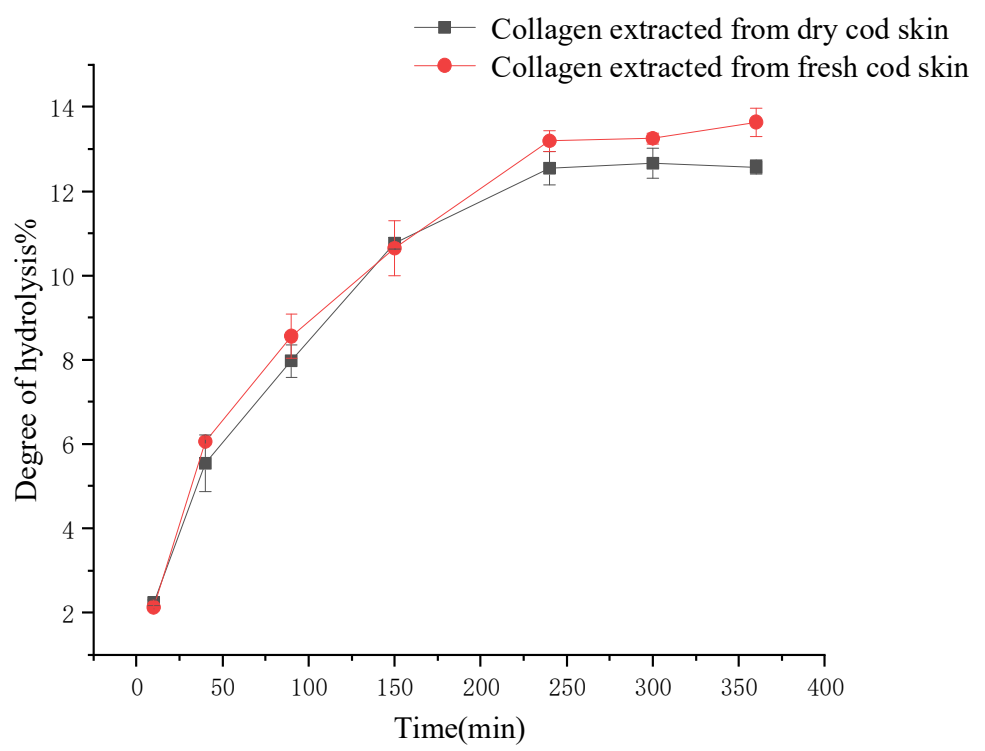

Fig. 1: Collagenase hydrolysis degree of collagen samples with respect to time variation. The circle symbol stands for collagen from fresh cod skins and the square symbol for collagen from dried cod skins 


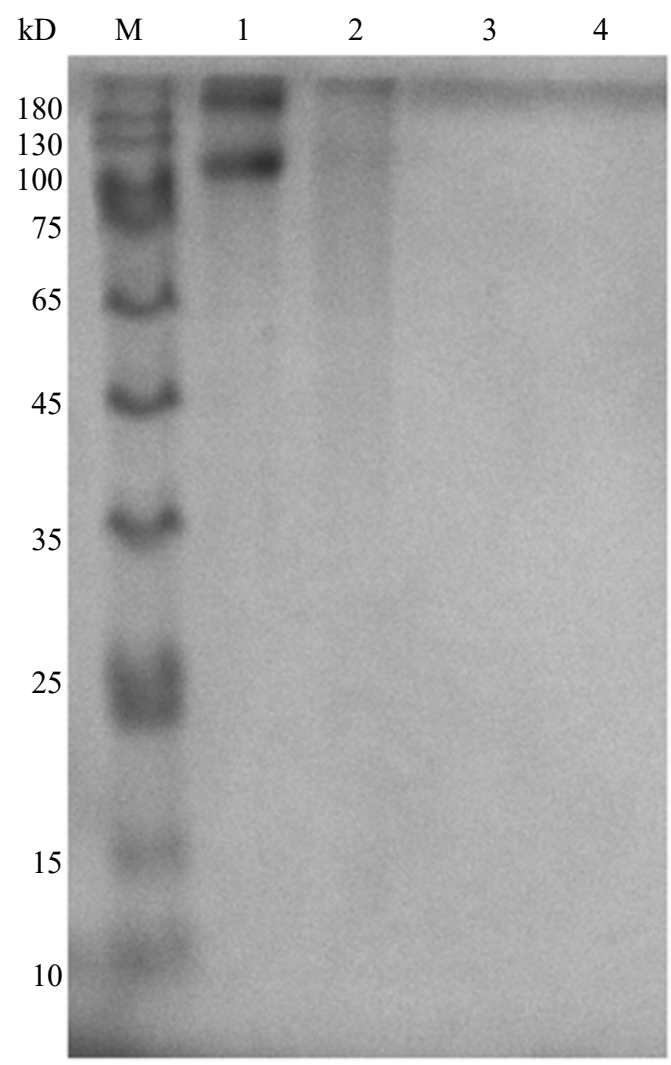

Fig. 2: SDS-PAGE patterns of collagen and collagen peptides. M: Protein markers; 1: Collagen extracted from fresh cod skin; 2 : Collagen extracted from dried cod skin; 3: PFC (peptides from fresh cod skin); 4: PDC (peptides from dried cod skin)

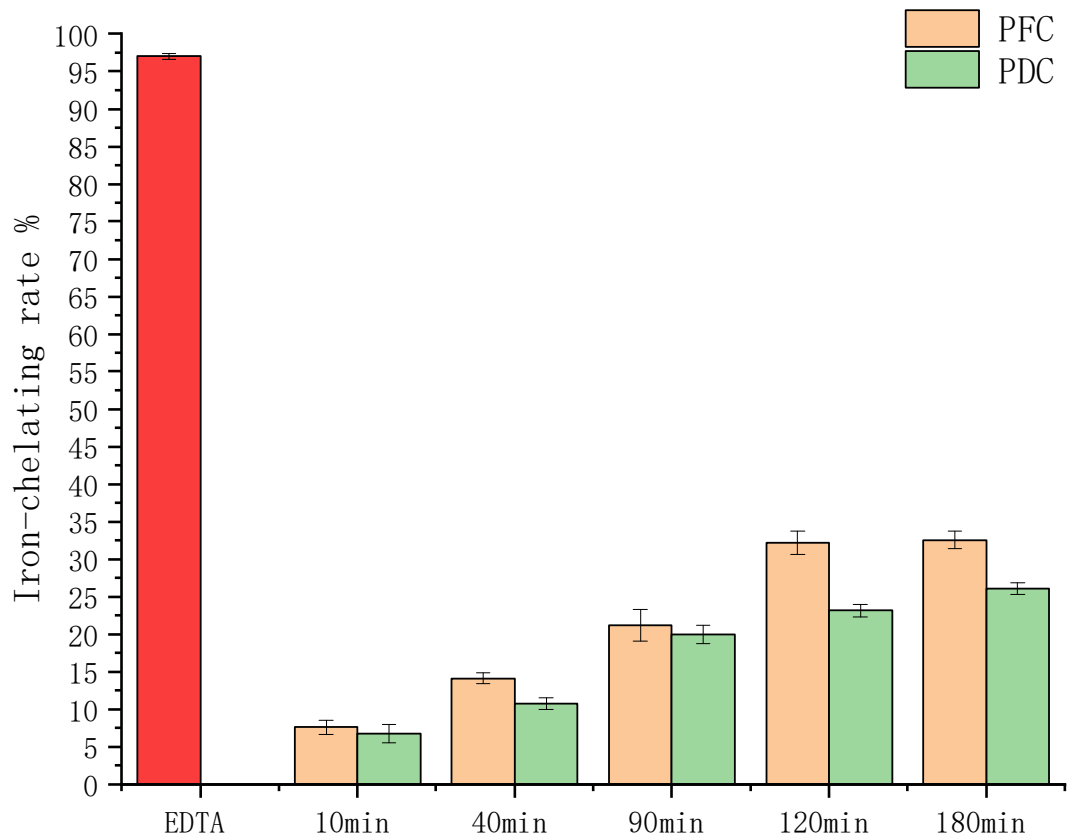

Fig. 3: Chelating activity of collagen against ferrous ion at different hydrolysis times. Orange represent PFC (peptides from fresh cod skin) and green represent PDC (peptides from cod skin) 

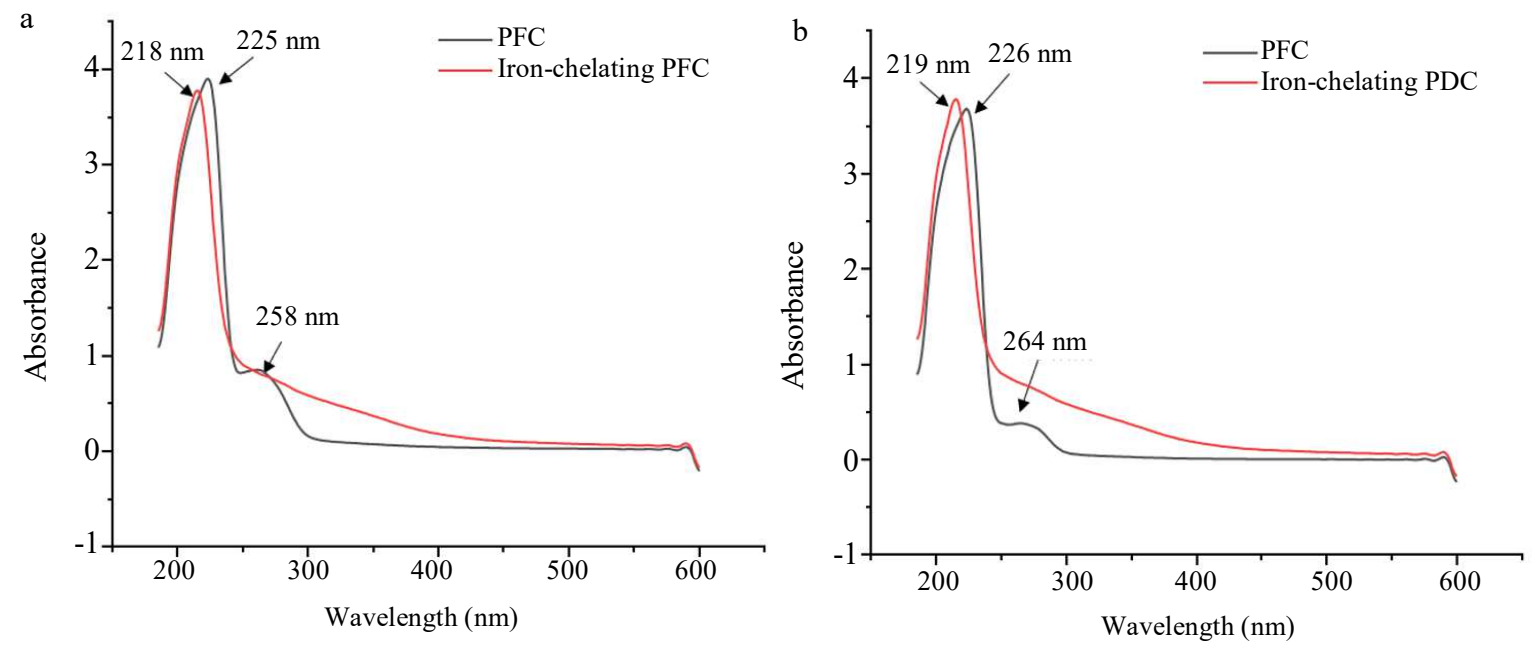

Fig. 4: UV absorption spectra of collagen peptide and iron chelate of collagen peptide. UV spectra of peptides from fresh cod skin (PFC) and iron chelating PFC (a). UV spectra of PDC (peptides from dried cod skin) and iron chelating PDC (b)

Figure 5 (b) shows the FTIR of PFC and PDC chelated with ferrous ion respectively. When peptides chelate ferrous ion, the absorption peaks of $\mathrm{N}-\mathrm{H}$ shifted from 3269.45and 3331.36to 3335.32 and $3334.98 \mathrm{~cm}^{-1}$, respectively. The absorption peaks of -COO- shifted from 1398.76 and 1393.83 to 1438.89 and $1419.78 \mathrm{~cm}^{-1}$, respectively.

\section{Analysis of Electron Microscopy}

The images of scanning electron microscope were made to observe the surface fiber structure of PFC, PDC and chelates with ferrous ion at 2000 times (Fig. 6). It can be seen from the figure that the surface of PFC and
PDC is relatively smoother. After the peptides are chelated with $\mathrm{Fe}^{2+}$, it can be found that the surface becomes finer granular.

\section{Circular Dichroism Analysis}

Figure 7 (a) and Fig. 7 (b) show the information of CD for collagen from fresh and dried cod skin, respectively. In Fig. 7 (a), there is a pronounced negative band at 197 $\mathrm{nm}$. A positive band was observed at $203 \mathrm{~nm}$ and a pronounced negative band at $214 \mathrm{~nm}$. In Fig. 7 (b), two negative peaks can be observed at 196 and 206nm.

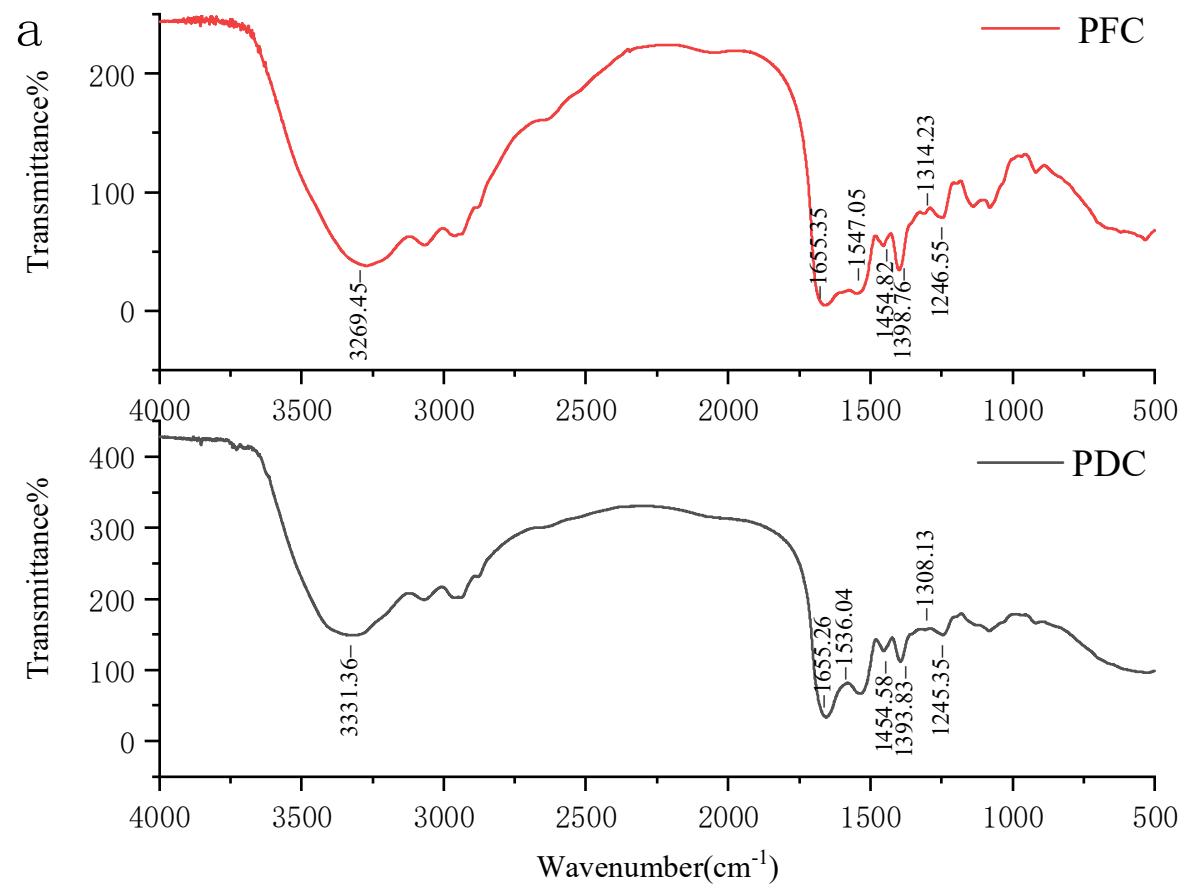




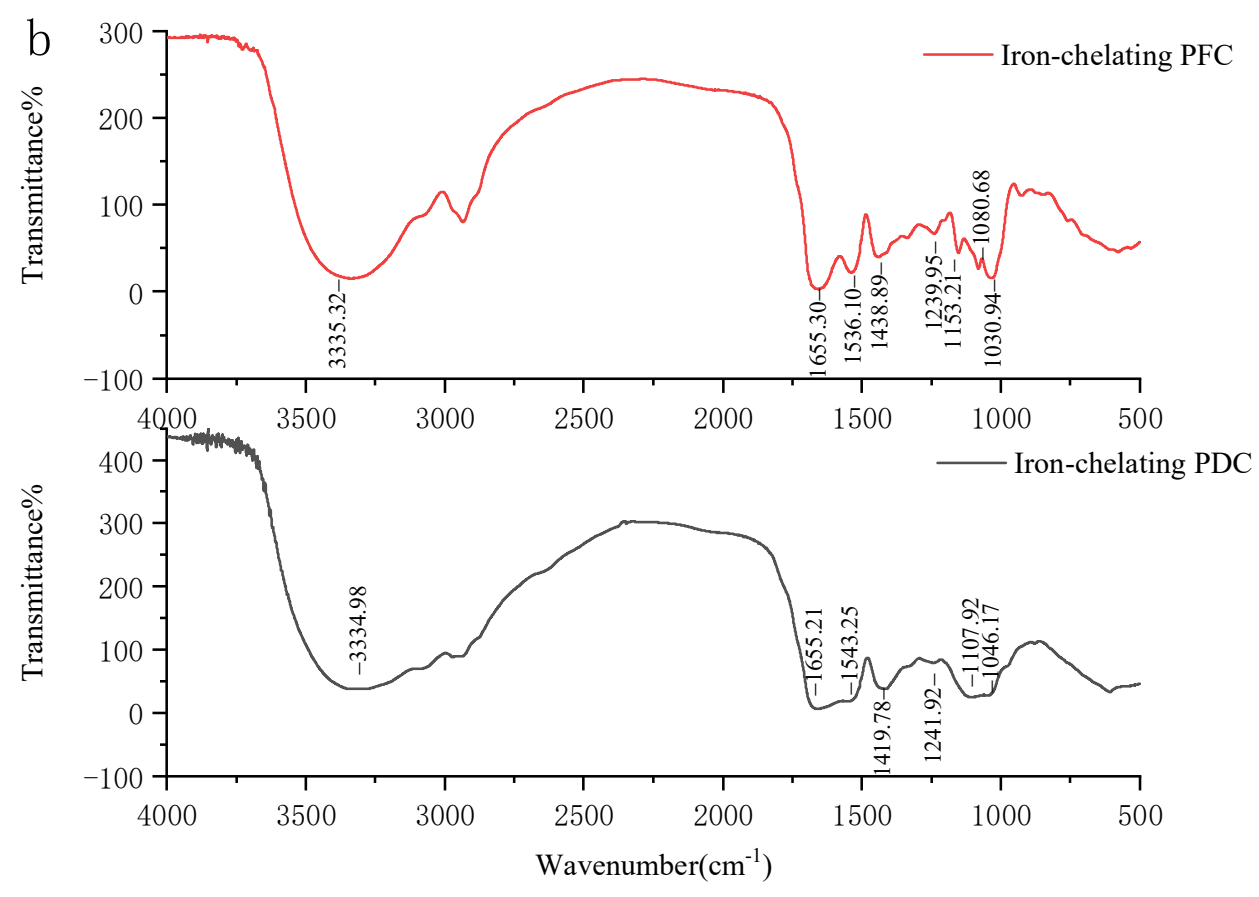

Fig.5: FTIR of PFC (peptides from fresh cod skin) and PDC (peptides from dried cod skin) (a). FTIR of iron chelation with PFC and PDC (b)

a

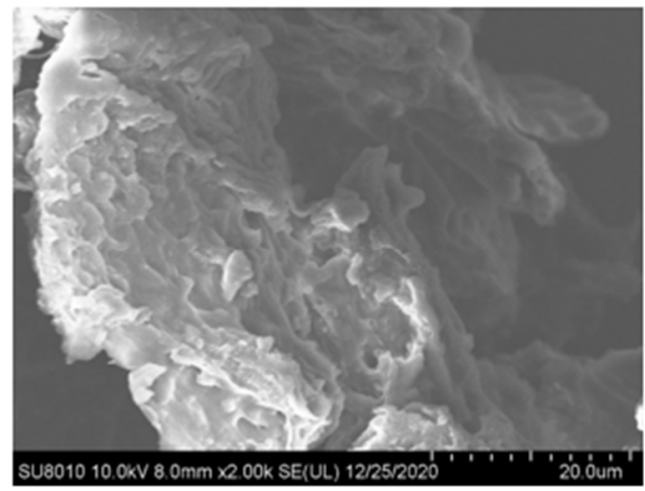

$\mathrm{C}$

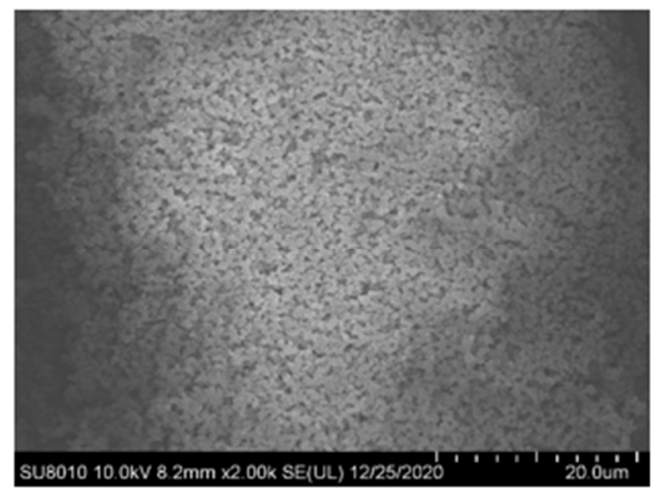

b

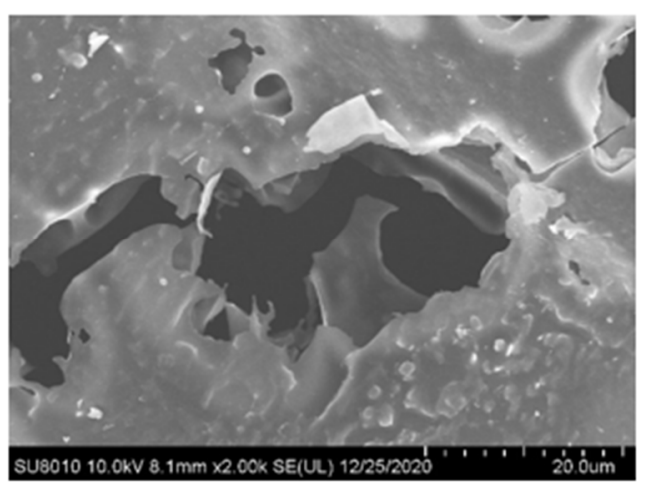

d

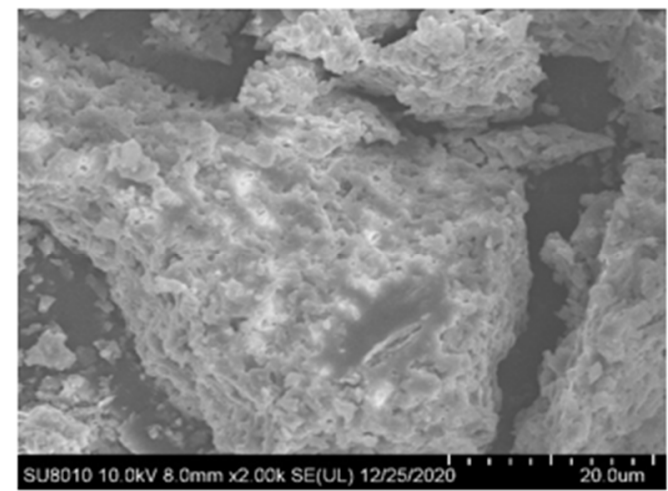

Fig.6: Scanning electron microscope images of collagen peptides and chelates. (a) PFC (peptides from fresh cod skin); (b) PDC (peptides from dried cod skin); (c) PFC chelate ferrous ions; (d) PDC chelate ferrous ions 

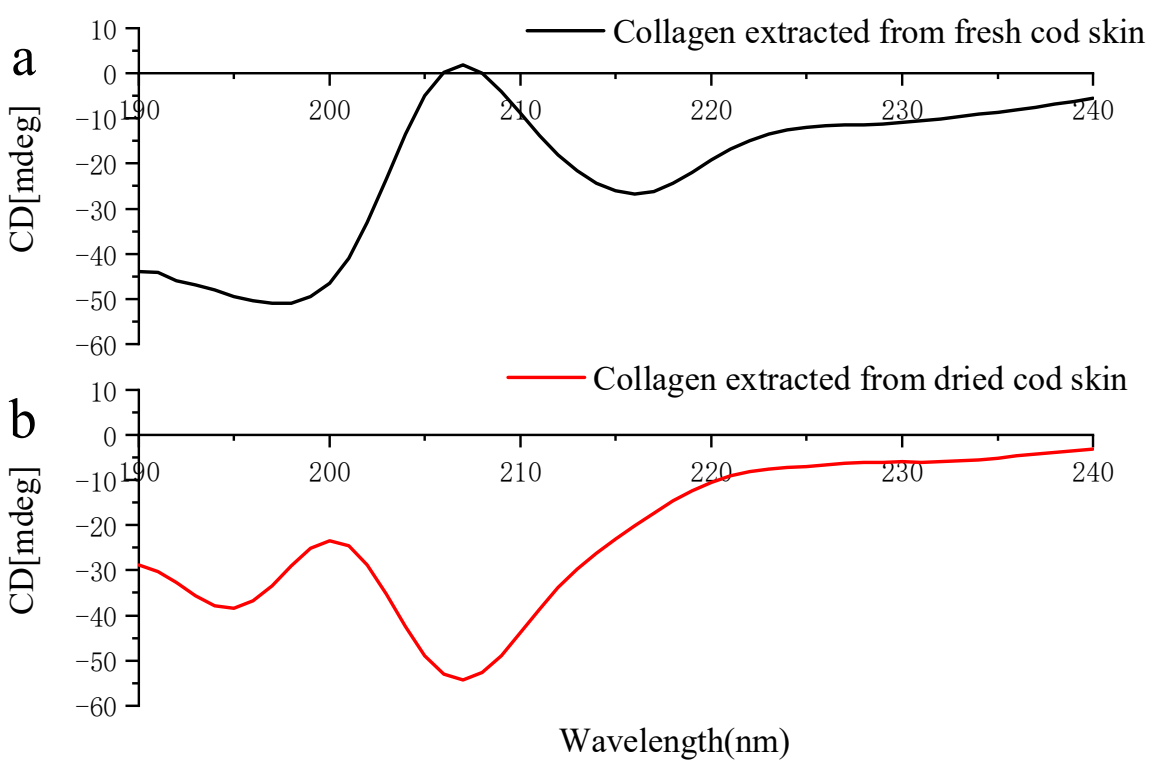

Fig.7: Circular dichroism spectra of collagen extracted from fresh and dried cod skin

\section{Discussion}

The fresh cod skin had $34.15 \%$ crude protein content and $2.6 \%$ hydroxyproline. According to the conversion coefficient of 12.5 (Edwards and O'Brien, 1982), the content of collagen was $32.5 \%$, accounting for $95.17 \%$ of the total protein content. Zhu et al. (2019) found that the content of protein, moisture, fat and ash in grass carp skin were $32.42,62.07,4.92$ and $0.51 \%$, respectively. Tilapia skin contained protein, moisture, ash and ash of 21.89, 64.10, 11.70 and $2.27 \%$ (Li et al., 2018). The moisture content of cod skin was similar to that of grass carp skin and Tilapia skin, but the protein content of cod skin was higher. But the research showed that eel skin (Veeruraj et al., 2013) and brown backed toadfish skin (Senaratne et al., 2006) contained $90.05,90.3 \%$ protein and $75.89,73.4 \%$ moisture, respectively, which were much higher than cod skin. Data show that cod skin can be a good material for collagen extraction.

According to the determination of DH, the tendency of the hydrolysate curve is similar to those previously reported for hydrolysates from goby muscle proteins (Nasri et al., 2012), proteins of Atlantic salmon (Kristinsson and Rasco, 2000) and sardinella (Khaled et al., 2012). The general trend showed that the DH values of the two are similar and the DH of collagen from fresh skin was a little higher than that from dried skin.

It was known that collagen was a triple helix structure composed of polypeptide chains (Zhang et al.,
2009). According to the results of FTIR found that the collagen extractedis type I collagen and the secondary structure of collagen extracted from fresh and dried cod skin was the same. The conclusion was consistent with Baltic cod skin (Skierka and Sadowska, 2007). But the bands of collagen extracted from dried cod skin were not obvious, it might be caused by the fracture of some bonds during the drying process. This may affect the formation of bands.

In order to verify that peptide can bind with ferrous ion, the determination of iron-chelating rate is necessary. The trend of iron-chelating rate is similar to the previously reported by $\mathrm{Wu}$ et al. (2017). By comparing the data of PDC and PFC, it is found that PFC has a better chelating activity of ferrous ion. It may be due to some bond was broken in the PDC.

$\mathrm{UV}$-Vis spectrum is closely related to the structure of a polypeptide chain, such as $-\mathrm{COOH},-\mathrm{CONH}_{2}$ groups and $n \rightarrow \pi *$ transition of $\mathrm{C}=\mathrm{O}$ in peptide bond. CO-, $\mathrm{COO}-$ and $-\mathrm{NH}$ are chromogenic groups with absorption peaks at $230 \mathrm{~nm}$. The absorption peaks of tyrosine and phenylalanine were at 250 and $280 \mathrm{~nm}$ (Lin and Liu, 2006). Collagen containing aromatic amino acids had absorption peaks at near $250 \mathrm{~nm}$. When peptides chelate with ferrous ion, the maximum absorption wavelengths were shift. The chelates will change the electron transition of the corresponding atom, so that the UV absorption performance will be changed, which also proves that the chelate reaction was occurred. 
The secondary structure of proteins can be effectively studied by FTIR spectroscopy. The wavenumber of FTIR is directly related to the configuration of collagen (Ahmad et al., 2010). The results show that there are more $\mathrm{NH}$ groups involved in hydrogen bonding in PFC than in PDC. The absorption peaks in the amide II band indicate the existence of $\alpha$-helical, $\beta$-folding and $\beta$-corner in the secondary structure of collagen peptide. The absorption peaks in the amide III band indicate the stretching of C-N and the bending of $\mathrm{N}-\mathrm{H}$. When PFC and PDC chelated with ferrous ion, the results show that both $\mathrm{N}-\mathrm{H}$ and -COOreacted with ferrous ion. It's involved in the chelation reaction. The absorption peak changes from unimodal to bimodal at about $1100 \mathrm{~cm}^{-1}$, which also indicates that ferrous ion has a strong binding effect with the amino group in the polypeptide chain (Zhao et al., 2014).

According to analysis of scanning electron microscope, the peptide can chelate with ferrous ion successfully and after chelating the structure of the peptide is changed. The collagen peptides hydrolyzed from fresh cod skin and dried cod skin have good chelating ability with ferrous ions. This is consistent with the results of UV-vis and FTIR spectrum.

Circular Dichroism (CD) is an effective technique to determinate the secondary structure of protein (Yang et al., 2021). It can display the information of alpha chains, random coils and triple helices. Natural collagen exhibited the maximum positive peak around $220 \mathrm{~nm}$ and the maximum negative peak at 195-197nm, indicating that it had a complete triple helix structure (Wang et al., 2020; Yang et al., 2015). Collagen extracted from fresh skin has two pronounced negative band and a positive band. It indicate that it is a typical feature of a random coil structure (Alves et al., 2017) and the collagen has been partially denatured upon extraction (Carvalho et al., 2018). Collagen extracted from dried skin has two negative peaks, which indicated that the collagen extracted from dried cod skin also had undergone denaturation. This may caused by the strong acid during the process of collagen extraction and the high temperature during drying process.

\section{Conclusion}

Cod skin, as a by-product of processing, is a valuable material for collagen extraction. In this study, the collagen was extracted from cod skin to improve the utilization rate of cod byproducts. The basic physicochemical properties of collagen extracted from fresh and dried fish skin as well as enzymatic hydrolysates chelating with ferrous ion were analyzed. The results of this study showed that there was no significant difference in the physical and chemical properties of collagen extracted from dried cod skin and fresh cod skin. The protein content of cod skin is in a high level and the main protein is collagen, which accounted for $95.17 \%$. Cod skin is a high-quality material for extracting collagen. The $\mathrm{DH}$ and chelating ability of fresh cod skin extracted collagen were slightly higher than those from dried cod skin. UV-Vis spectroscopy, FTIR and SDS-PAGE proved that the secondary structure of fresh and dried cod skin extracted collagen was basically the same. The result of $\mathrm{CD}$ proved that fresh and dried fish skin extracted collagen does not have a complete triple helix structure, which may be destroyed in the process of extraction. Fresh cod skin is often used as raw material in experiments and production. However, fresh cod skin is perishable and hard to store. The above consequences showed that fresh fish skin was better than dried fish skin, but there was no significant difference between them. Considering the storage conditions and transportation costs of fresh cod skin, dried cod skin is more economical. Further work is going to isolate and purify collagen peptides, compare and analyze the peptide segments, determine their iron chelating rate and antioxidant activity. Their properties and structure will be conducted in-depth analysis. Overall, the findings suggest that the dried cod skin can replace the fresh cod skin in the extraction process of collagen and the collagen peptide is a good choice to produce iron supplementation.

\section{Acknowledgement}

This research is supported by the Science and Technology Project of Zhejiang, Province, China [grant number LGN19C200018] and the Fundamental Research Funds for the Provincial Universities of Zhejiang [No 2020YW34]. The founding sponsor had no role in the design of the study; in the collection, analyses, or interpretation of data; in the writing of the manuscript and in the decision to publish the results.

\section{Author's Contributions}

Mengqian Chen: Conducts the experiments and writes the paper.

Cen Chen: Dada analysis.

Junchao Wu and Jiayuan Bi: Conducts particle experiments.

Han Jiang and Gangrong Huang: Provides ideas and helped to revise the article.

\section{Ethics}

The authors declare their responsibility for any ethical issues that may arise after the publication of this manuscript. 


\section{References}

Ahmad, M., Benjakul, S., \& Nalinanon, S. (2010). Compositional and physicochemical characteristics of acid solubilized collagen extracted from the skin of unicorn leatherjacket (Aluterus monoceros). Food Hydrocolloids, 24(6-7), 588-594. https://doi.org/10.1016/j.foodhyd.2010.03.001

Ahmed, M., Verma, A. K., \& Patel, R. (2020). Collagen extraction and recent biological activities of collagen peptides derived from sea-food waste: A review. Sustainable Chemistry and Pharmacy, 18, 100315. https://doi.org/10.1016/j.scp.2020.100315

Alves, A. L., Marques, A. L., Martins, E., Silva, T. H., \& Reis, R. L. (2017). Cosmetic potential of marine fish skin collagen. Cosmetics, 4(4), 39. https://doi.org/10.3390/cosmetics4040039

Carvalho, A. M., Marques, A. P., Silva, T. H., \& Reis, R. L. (2018). Evaluation of the potential of collagen from cod fish skin as a biomaterial for biomedical applications. Marine Drugs, 16(12), 495. https://doi.org/10.3390/md16120495

Chen, M., Ji, H., Zhang, Z., Zeng, X., Su, W., \& Liu, S. (2019). A novel calcium-chelating peptide purified from Auxisthazard protien hydrolysate and its binding properties with calcium. Journal of Functional Foods, 60, 103447. https://doi.org/10.1016/j.jff.2019.103447

Chen, Q., Guo, L., Du, F., Chen, T., Hou, H., \& Li, B. (2017). The chelating peptide (GPAGPHGPPG) derived from Alaska pollock skin enhances calcium, zinc and iron transport in Caco-2 cells. International Journal of Food Science and Technology, 52(5), 1283-1290. https://doi.org/10.1111/ijfs. 13396

De la Hoz, L., Ponezi, A. N., Milani, R. F., da Silva, V. S. N., De Souza, A. S., \&Bertoldo-Pacheco, M. T. (2014). Iron-binding properties of sugar cane yeast peptides. Food Chemistry, 142, 166-169. https://doi.org/10.1016/j.foodchem.2013.06.133

Eckert, E., Lu, L., Unsworth, L.D., Chen, L., Xie, J. and Xu, R. (2016). Biophysical and in vitro absorption studies of iron chelating peptide from barley proteins. Journal of Functional Foods, 25, 291-301. https://doi.org/10.1016/j.jff.2016.06.011

Edwards, C. A., \& O’Brien, W. D., Jr. (1980). Modified assay for determination of hydroxyproline in a tissue hydrolyzate. Clinica Chimica Acta, 104, 161-167. https://doi.org/10.1016/0009-8981(80)90192-8

El-Hawary, M. F. S., El-Shobaki, F. A., Kholeif, T., Sakr, R., \& El-Bassoussy, M. (1975). The absorption of iron, with or without supplements of single amino acids and of ascorbic acid, in healthy and Fe-deficient children. British Journal of Nutrition, 33(3), 351-355. https://doi.org/10.1079/BJN19750040
Gómez, L. J., Gómez, N. A., Zapata, J. E., López-García, G., Cilla, A., \& Alegría, A. (2020). Optimization of the Red Tilapia (Oreochromis spp.) Viscera Hydrolysis for Obtaining Iron-Binding Peptides and Evaluation of in Vitro Iron bioavailability. Foods, 9(7), 883. https://doi.org/10.3390/foods9070883

Hurrell, R., \& Egli, I. (2010). Iron bioavailability and dietary reference values. The American Journal of Clinical Nutrition, 91(5), 1461S-1467S. https://doi.org/10.3945/ajcn.2010.28674F

Ji, L. E. I., Zhang, Y., Chen, X. G., Zhang, M. Q., Lin, B. A. I., Huang, C. Y., \& Ivan, O. M. (2012). Assessment of iron bioavailability in ten kinds of Chinese wheat flours using an in vitro digestion/Caco-2 cell model. Biomedical and Environmental Sciences, 25(5), 502-508. https://doi.org/10.3967/0895-3988.2012.05.002.

Jiang, H., Zhang, W., Chen, F., Zou, J., Chen, W., \& Huang, G. (2019). Purification of an iron-binding peptide from scad (Decapterus maruadsi) processing by-products and its effects on iron absorption by Caco-2 cells. Journal of Food Biochemistry, 43(7), e12876. https://doi.org/10.1111/jfbc. 12876

Khaled, H. B., Ghlissi, Z., Chtourou, Y., Hakim, A., Ktari, N., Fatma, M. A., ... \& Nasri, M. (2012). Effect of protein hydrolysates from sardinelle (Sardinella aurita) on the oxidative status and blood lipid profile of cholesterol-fed rats. Food Research International, 45(1), 60-68. https://doi.org/10.1016/j.foodres.2011.10.003

Kristinsson, H. G., \& Rasco, B. A. (2000). Biochemical and functional properties of Atlantic salmon (Salmo salar) muscle proteins hydrolyzed with various alkaline proteases. Journal of Agricultural and Food Chemistry, 48(3), 657-666. https://doi.org/10.1021/jf990447v

Le Vo, T. D., Pham, K. T., Van Le, V. M., Lam, H. H., Huynh, O. N., \& Vo, B. C. (2020a). Evaluation of iron-binding capacity, amino acid composition, functional properties of Acetes japonicus proteolysis and identification of iron-binding peptides. Process Biochemistry, 91, 374-386. https://doi.org/10.1016/j.procbio.2020.01.007

Le Vo, T. D., Vo, B. C., Tran, L. T. T., Nguyen, L. V. T., Nguyen, P. T., Le, D. T., ... \& Bui, P. T. (2020b). Calcium-and iron-chelating activity and functional properties of salmon by-product proteolysis. https://doi.org/10.21203/rs.3.rs-121864/v1

Li, J., Wang, M., Qiao, Y., Tian, Y., Liu, J., Qin, S., \& Wu, W. (2018). Extraction and characterization of type I collagen from skin of tilapia (Oreochromis niloticus) and its potential application in biomedical scaffold material for tissue engineering. Process Biochemistry, 74, 156-163. https://doi.org/10.1016/j.procbio.2018.07.009 
Lin, Y. K., \& Liu, D. C. (2006). Comparison of physicalchemical properties of type I collagen from different species. Food Chemistry, 99(2), 244-251. https://doi.org/10.1016/j.foodchem.2005.06.053

Ma, X., Liu, C., Song, W., Che, S., Wang, C., Feng, X., ... \& Dai, Y. (2019). Evaluating the efficacy of a ferrous-ion-chelating peptide from Alaska pollock frame for the improvement of iron nutritional status in rats. Food \& Function, 10(8), 4888-4896. https://doi.org/10.1039/C9FO00310J

Mazariegos, D. I., Pizarro, F., Olivares, M., Nuñez, M. T., \& Arredondo, M. (2004). The mechanisms for regulating absorption of $\mathrm{Fe}$ bis-glycine chelate and Fe-ascorbate in caco-2 cells are similar. The Journal of Nutrition, 134(2), 395-398. https://doi.org/10.1046/j.1365-277X.2003.00488.x

Muyonga, J. H., Cole, C. G. B., \& Duodu, K. G. (2004). Characterisation of acid soluble collagen from skins of young and adult Nile perch (Lates niloticus). Food Chemistry, 85(1), 81-89. https://doi.org/10.1016/j.foodchem.2003.06.006

Nasri, R., Bougatef, A., Ben Khaled, H., Nedjar-Arroume, N., KarraChaâbouni, M., Dhulster, P., \& Nasri, M. (2012). Antioxidant and free radical-scavenging activities of goby (Zosterisessor ophiocephalus) muscle protein hydrolysates obtained by enzymatic treatment. Food Biotechnology, 26(3), 266-279. https://doi.org/10.1080/08905436.2012.699203

Navas-Carretero, S., Pérez-Granados, A. M., Sarriá, B., Carbajal, A., Pedrosa, M. M., Roe, M. A., ... \& Vaquero, M. P. (2008). Oily fish increases iron bioavailability of a phytate rich meal in young iron deficient women. Journal of the American College of Nutrition, 27(1), 96-101. https://doi.org/10.1080/07315724.2008.10719680

Nomura, Y., Sakai, H., Ishii, Y., \& Shirai, K. (1996). Preparation and some properties of type I collagen from fish scales. Bioscience, Biotechnology and Biochemistry, 60(12), 2092-2094. https://doi.org/10.1271/bbb.60.2092

Rustad, T., Storrø, I., \&Slizyte, R. (2011). Possibilities for the utilisation of marine by-products. International Journal of Food Science and Technology, 46(10), 2001-2014. https://doi.org/10.1111/j.13652621.2011.02736.x

Sampath Kumar, N. S., \& Nazeer, R. A. (2013). Characterization of acid and pepsin soluble collagen from the skin of horse mackerels (Magalaspiscordyla) and croaker (Otolithesruber). International Journal of Food Properties, 16(3), 613-621. https://doi.org/10.1080/10942912.2011.557796

Schenck, M. (1951). About the action of nascent nitrous acid on various nitrogen-containing organic compounds (on van Slyke's determination of amino nitrogen). https://doi.org/10.1515/bchm2.1951.286.1-6.270
Senaratne, L. S., Park, P. J., \& Kim, S. K. (2006). Isolation and characterization of collagen from brown backed toadfish (Lagocephalus gloveri) skin. Bioresource Technology, 97(2), 191-197. https://doi.org/10.1016/j.biortech.2005.02.024

Skierka, E., \& Sadowska, M. (2007). The influence of different acids and pepsin on the extractability of collagen from the skin of Baltic cod (Gadus morhua). Food Chemistry, 105(3), 1302-1306. https://doi.org/10.1016/j.foodchem.2007.04.030

Sousa, R. O., Martins, E., Carvalho, D. N., Alves, A. L., Oliveira, C., Duarte, A. R. C., ... \& Reis, R. L. (2020). Collagen from Atlantic cod (Gadus morhua) skins extracted using CO 2 acidified water with potential application in healthcare. Journal of Polymer Research, 27(3), 1-9. https://doi.org/10.1007/s10965020-02048-X

Toxqui, L., \& Vaquero, M. P. (2015). Chronic iron deficiency as an emerging risk factor for osteoporosis: a hypothesis. Nutrients, 7(4), 2324-2344. https://doi.org/10.3390/nu7042324

Toxqui, L., Pérez-Granados, A. M., Blanco-Rojo, R., Wright, I., González-Vizcayno, C., \& Vaquero, M. P. (2013). Effects of an iron or iron and vitamin Dfortified flavored skim milk on iron metabolism: a randomized controlled double-blind trial in irondeficient women. Journal of the American College of Nutrition, 32(5), 312-320. https://doi.org/10.1080/07315724.2013.826116

Veeruraj, A., Arumugam, M., \& Balasubramanian, T. (2013). Isolation and characterization of thermostable collagen from the marine eel-fish (Evenchelysmacrura). Process Biochemistry, 48(10), 1592-1602. https://doi.org/10.1016/j.procbio.2013.07.011

Wang, L., Wang, L., Su, C., Wen, C., Gong, Y., You, Y., ... \& Xiao, H. (2020). Characterization and digestion features of a novel polysaccharide-Fe (III) complex as an iron supplement. Carbohydrate Polymers, 249, 116812. https://doi.org/10.1016/j.carbpol.2020.116812

Wu, L., Zou, Y., Miao, Y., Zhang, J., Zhu, S., Zeng, M., \& $\mathrm{Wu}, \mathrm{H}$. (2019). Dietary gelatin enhances non-heme iron absorption possibly via regulation of systemic iron homeostasis in rats. Journal of Functional Foods, 59, 272-280. https://doi.org/10.1016/j.jff.2019.06.005

Wu, W., Li, B., Hou, H., Zhang, H., \& Zhao, X. (2017). Identification of iron-chelating peptides from Pacific cod skin gelatin and the possible binding mode. Journal of Functional Foods, 35, 418-427. https://doi.org/10.1016/j.jff.2017.06.013

Wu, W., Yang, Y., Sun, N., Bao, Z., \& Lin, S. (2020). Food protein-derived iron-chelating peptides: The binding mode and promotive effects of iron bioavailability. Food Research International, 131, 108976. https://doi.org/10.1016/j.foodres.2020.108976 
Yang, H., Wang, H., Zhao, Y., Wang, H., \& Zhang, H. (2015). Effect of heat treatment on the enzymatic stability of grass carp skin collagen and its ability to form fibrils in vitro. Journal of the Science of Food and Agriculture, 95(2), 329-336. https://doi.org/10.1002/jsfa.6724

Yang, X., Yu, X., Yagoub, A. G., Chen, L., Wahia, H., Osae, R., \& Zhou, C. (2021). Structure and stability of low molecular weight collagen peptide (prepared from white carp skin)-calcium complex. LWT, 136, 110335. https://doi.org/10.1016/j.lwt.2020.110335

Yao, P., Wang, H., Wang, H., Li, Y., Wang, M., \& Zhang, H. (2012). Biochemical and physiological characterization of collagen from the skin of bighead carp (Aristichthys nobilis). Journal of Food, Agriculture \& Environment, 10(3/4), 92-98.
Zhang, J., Duan, R., Tian, Y., \& Konno, K. (2009). Characterisation of acid-soluble collagen from skin of silver carp (Hypophthalmichthys molitrix). Food Chemistry, 116(1), 318-322. https://doi.org/10.1016/j.foodchem.2009.02.053

Zhao, L., Huang, S., Cai, X., Hong, J., \& Wang, S. (2014). A specific peptide with calcium chelating capacity isolated from whey protein hydrolysate. Journal of Functional Foods, 10, 46-53. https://doi.org/10.1016/j.jff.2014.05.013

Zhu, S., Yuan, Q., Yang, M., You, J., Yin, T., Gu, Z., ... \& Xiong, S. (2019). A quantitative comparable study on multi-hierarchy conformation of acid and pepsinsolubilized collagens from the skin of grass carp (Ctenopharyngodon idella). Materials Science and Engineering: $\quad$ C, 96, 446-457. https://doi.org/10.1016/j.msec.2018.11.043 